\title{
The Reflections on the using of Oracle Data Modeler in Creating Entity Relationship Diagram (ERD)
}

\author{
Nor Anisah Mohd Saad ${ }^{\mathrm{a}}$, Mageswary Muniandi ${ }^{\mathrm{b}}$ \\ a anisaad@puo.edu.my, ${ }^{b}$ mageswary@puo.edu.my \\ ${ }^{a}$ Ungku Omar Polytechnic, Jalan Raja Musa Mahadi, 31400 Ipoh, Perak Malaysia \\ ${ }^{b}$ Ungku Omar Polytechnic, Jalan Raja Musa Mahadi, 31400 Ipoh, Perak Malaysia
}

\begin{abstract}
Abstract: This study aims to look at the use of Oracle Data Modeler, as a tool used for development of an ERD. This data modelling developed by Oracle Corporation provide practical explanations and references that can change the way data modelling taught in the classroom. The tools provided by Oracle Data Modeler are better and easier to use in order to produce the logical and physical structure of a database. This tool had been shared among lecturers and students through sharing and transfer knowledge course and the respondents gave reflections on this tool. ERD and Relational Model developed automatically by completing the variables or data required through the form-fills interface method. This method helps students to develop ERD quickly, easily and accurately. Most respondents gave positive responses to the using of Data Modeler in terms of reactions of teaching or learning and impact to the skills. By using Oracle Data Modeler, students were able to implement correctly the creation of logical and physical model in the database design.
\end{abstract}

Keywords: Oracle Data Modeler; ERD; modelling

\subsection{INTRODUCTION}

Database Design is a compulsory course taken by students majoring in Diploma in Information Technology (Digital Technology), Polytechnic Malaysia. This course engages students to analyze business scenarios and create a data model as a conceptual representation of an organization's information. Students implement their database design by creating a logical database design using ERD (Entity Relationship Diagram) and physical database using SQL (Structured Query Language). Basic SQL syntax and the rules for constructing valid SQL statements reviewed in this course. This course culminates with a case study and project that challenges students to design, implement, and demonstrate a database solution for a business or organization. It emphasizes the specific concepts that need to be adhered to in order to develop a database. Students will be exposed to the basic concept of database development which is data modelling before developing a database, so student might have a great basic on data modelling concept, techniques and tools used. Database technology nowadays has transforms into most popular technology area, which serve to a better ways on how data managed in the organization worldwide. The rapid changes and the increased ways that data is managed creates an opportunities for database developer and company to produce current technology related with database. Database technology make a bigger move and transition from hierarchical databases to a network database and relational database technologies. Database technologies are core component that exists in many computing systems nowadays. The technology allow data to be stored and shared electronically and the amount of data contained in these systems continues to grow and increased dramatically. 


\subsection{RESEARCH BACKGROUND}

\subsection{Objectives}

The objectives of this study are:

a) To observe the reflections of using Oracle Data Modeler for learning knowledge.

b) To observe the reflections of using Oracle Data Modeler for skills obtained.

\subsection{Literature Review}

\subsubsection{Database \& Database Management System (DBMS)}

A database is a collection of organized data, to make data easily accessed and managed. It is a shared collection of logically related data and designed to meet the information needs of an organisation or purposes. A database is a system used to manage data on a computer system (Simanjuntak, 2013). The database consists of tables containing records. For example, a XYZ college database would have a Student table with a record for each student enrolled. Database architecture is a graphical and suggestive representation of the system elements and of the links between them. In the specialty, literature presented various database architecture types (J.Date, 2004). Database design is part of the database development process that involves analysis of problem specifications and requirements and provides all necessary findings for creating a logical data structure. Such a model comes close to what one considers a conceptual level or view (Date, 2004). Database Management System (DBMS) is a software that manages and controls access to the database. It enables users to define, create and maintain the database and provides controlled access to this database. In the database model, the DBMS is the software that supports and controls access to a database for every user process (Sudirman, 2009). It can manages the storage and retrieval of data in the database and processes data according to the database schema. A database management system (DBMS) provides the tools and other facilities to create database files, each which is a compilation of organized data (Stair \& Reynolds, 2018). Database design is the process of designing the logical and physical structure of one or more databases to accommodate the information needs of the users in an organization for a defined set of applications. Many of the database technologies nowadays have reduced their coverage on the traditional ERD and now focus more on UML (Gravino, 2010). With the growing popularity of Unified Modeling Language (UML),

\subsubsection{Data Modeling}

The data model is one part of the conceptual design process. It focuses on what data should be stored in the database and to put this in the context of the relational database, the data model used to design the relational tables. Data modeling involves building an entity relationship diagram (ERD), Unified Modelling Language (UML) and others that describes the entire data and the relationship between the data before developing the database in any RDBMS. It is also known as a technique or tools used to model logical data before being converted to physical data that is program codes (normally using SQL language). The data model is one part of the conceptual design process. The requirements analysis usually done at the same time as the data modeling. As information is collected, data objects identified and classified as entities, attributes, or relationship; assigned names and, defined using terms familiar to the end-users. Then, all the data and information will be summarize in one diagram to represent the flows at data and relationship among data. The objects then modeled and analyzed using an Entity Relationship (ER) diagram (Bagui, Sikha, 2011). Data modeling is probably the most labor intensive and time-consuming part of the development process. The goal of the data model is to make sure that the all data objects required by the database completely and accurately represented. Because the data model uses easily understood notations and natural language, it will reviewed and verified as correct by the end-users. Entity Relationship Diagram (ERD) is a conceptual data model that views and represent the real world as entities and relationships. A basic function of ERD used visually to represent data objects. A relational database that contains the classes of an application will be highly applicationspecific while a relational database used by many more applications (Hitchman, 2002). A logical data model expected to capture entity types, attributes, relationships, and constraints. The basic object of the ER model represents an entity, which is a "thing" in the real world with an independent existence (Elmasri, 2004). 


\subsubsection{Oracle Data Modeler}

Oracle SQL Developer Data Modeler is a new, graphical data-modeling tool that facilitates and enhances communication between data architects, database administrators, application developers and users, and simplifies the data modeling development process itself. Using SQL Developer Data Modeler users can create, browse and edit, logical, relational, physical, multi-dimensional, and data type models. Oracle, which controls over $48 \%$ of the relational database management software, has recently introduced a stand- alone database modeling and design tool called SQL Developer Data Modeler (Oracle, 2011). This tool provides a full spectrum of data and database modeling tools and utilities, including modeling for Entity Relationship Diagrams (ERD), Relational (database design), and Data Type with forward and reverse engineering and DDL. The generation of DDL scripts in Oracle Data Modeler improves productivity and promotes the use of standards in coding. The introduction of this tool illustrates Oracle's commitment to improve developer productivity and to facilitate the improved quality done by the database developer community and their users. The role of SQL Developer Data Modeler is to simplify data modeling development tasks and serves as a powerful communication tool between developers and business users. (Hitchman, 2002).

\subsection{RESEARCH METHODOLOGY}

This research focus on developing the Entity Relationship Diagram (ERD) by using Oracle Data Modeler. The current method used in teaching ERD is to use Microsoft Word or Microsoft Access, which is not standardize in terms of formatting and notation. By introducing Oracle Data Modeler, students taught to develop ERD using the tools provided by this Data Modeler. Figure 1 shows the steps to develop a database, which involves data modelling process.

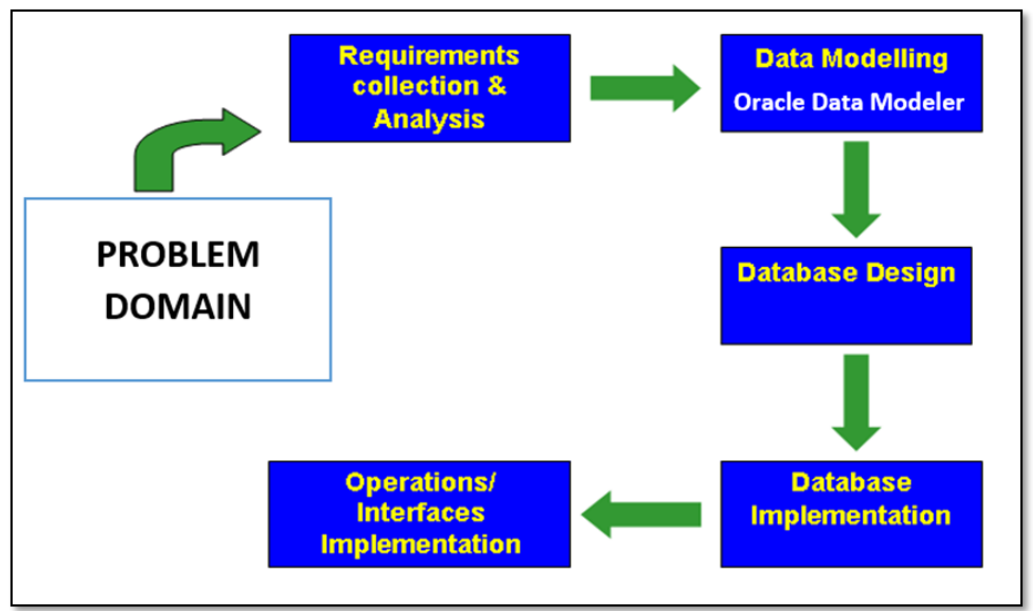

Figure 1: Steps involved in database development

\subsection{Partipants}

In total, there are 118 participants involved in this study. From the 118 participants, 10 are lecturers and the rest are the students from programme Diploma in Information Technology (Digital Technology) Ungku Omar Polytechnic, Perak Malaysia. The students are currently study in Semester 2 and enrol for Database Design (DFC20123) course. DFC20123 is a common core subject, which is student must take and pass this subject, as it is a prerequisite to other subject.

\subsection{Instruments}

A set of questionnaires with 5 scales point was given to 10 lecturers and 108 students from 3 classes to assess the level of understanding in teaching/ learning and skills improvement acquired from this Oracle Data Modeler tool. Questionnaires for lecturers given immediately after the training by hardcopy, and for students, the questionnaires was spread by using Google Form. 
The questionnaires consist of 2 part. Part 1 focus on reflections for learning knowledge and Part 2 focus on reflections on skills obtained from the Oracle Data Modeler usage. For Part 1 (reaction for learning knowledge) there are 5 questions provided (L1 - L5) and for Part 2 (reflections on skills obtained), also 5 questions provided (S1 - S5). The five-point Likert scale range from 1 (strongly disagree) to 5 (strongly agree) was used to express the agreement of the statement.

\subsection{Procedures}

A short course to explain the use of ERD construction tools and techniques using Data Modeler implemented for course lecturers. A questionnaire distributed to assess the level of understanding, improvement of skills competencies and the level of confidence to share knowledge with their respective students. In total, 10 lecturers answered the questionnaire by giving a 5-points scale to answer the research questions. Each of lecturers sharing the knowledge on ERD development using Data Modeler to their respective class students. This knowledge dissemination process involves semester 2 students who take the Database Design course (DFC20123). Figure 2 shows summarize of procedures used to study the refections from the respondents.

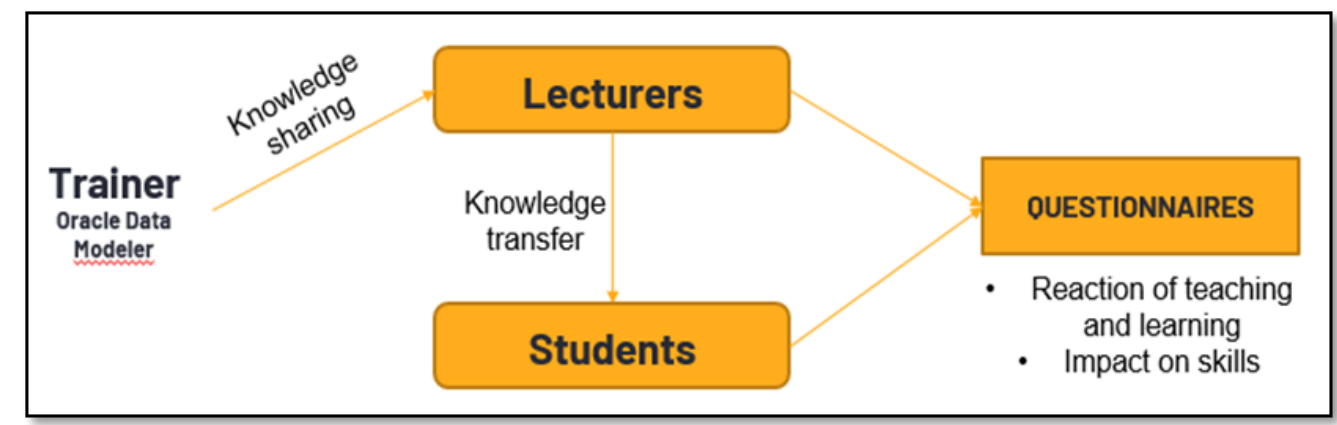

Figure 2: Procedures for reflections

\subsection{RESULTS AND FINDINGS}

\subsection{Student's performance}

According to Nunnally (1978), the value of 0.7 is an acceptable for a reliable construct. Therefore, from the result, the value of Cronbach Alpha in this study is 0.890 as in Figure 3 and it were reliable.

\begin{tabular}{|c|c|c|}
\hline $\begin{array}{l}\text { Cronbach's } \\
\text { Alpha }\end{array}$ & $\begin{array}{c}\text { Cronbach's } \\
\text { Alpha Based } \\
\text { on } \\
\text { Standardized } \\
\text { Items }\end{array}$ & $\mathrm{N}$ of Items \\
\hline .890 & .893 & 10 \\
\hline
\end{tabular}

Figure 3: Reliability Analysis

Based on the study-conducted shows that the majority respondent (Students) gave positive feedback by rating score 4 and 5 (agree and strongly agree) for Part 1(reflections for learning knowledge) and Part 2 (reflections on skills obtained). It shown in Figure 4 below by Mean value for each questions, which is in between 4 and 5 . 


\begin{tabular}{|l|r|r|r|r|r|r|}
\hline & $N$ & Minimum & Maximum & Sum & Mean & Std. Deviation \\
\hline L1 & 108 & 2 & 5 & 480 & 4.44 & .660 \\
L2 & 108 & 3 & 5 & 481 & 4.45 & .617 \\
L3 & 108 & 3 & 5 & 469 & 4.34 & .614 \\
L5 & 108 & 3 & 5 & 472 & 4.37 & .650 \\
S1 & 108 & 3 & 5 & 471 & 4.36 & .618 \\
S2 & 108 & 3 & 5 & 476 & 4.41 & .581 \\
S3 & 108 & 2 & 6 & 476 & 4.41 & .670 \\
S4 & 108 & 3 & 5 & 470 & 4.35 & .674 \\
S5 & 108 & 2 & 6 & 477 & 4.42 & .685 \\
Valid N (listwise) & 108 & 2 & 5 & 495 & 4.58 & .643 \\
\hline
\end{tabular}

Figure 4: Descriptive analysis

Based on Figure 5, most students gave positive feedback by rating score 4 and 5 (agree and strongly agree) for Part 1(reflections for learning knowledge) and Part 2 (reflections on skills obtained).

\begin{tabular}{|c|c|c|c|c|c|}
\hline \multicolumn{3}{|l|}{ Learning Reaction } & \multirow{2}{*}{\multicolumn{2}{|c|}{$\begin{array}{c}\text { Agree \& Strongly } \\
\text { Agree } \\
\text { (Score } 4 \text { and 5) }\end{array}$}} & \multirow{2}{*}{$\begin{array}{c}\text { Average } \\
\text { score } \\
4 \& 5\end{array}$} \\
\hline & 4 & 5 & & & \\
\hline 1. The lessons learned from this course are important. & 7 & 90 & 97 & 92.6 & \multirow{5}{*}{92.4} \\
\hline 2. The lessons helps in learning necessary knowledge & 2 & 93 & 95 & 93.5 & \\
\hline 3. The course provides the necessary knowledge & 8 & 89 & 97 & 92.6 & \\
\hline 4. The knowledge gained can be relate to the theory concept & 4 & 95 & 99 & 90.7 & \\
\hline 5. The knowledge gained improve confidence to teach/ learn & 7 & 84 & 91 & 92.6 & \\
\hline \multicolumn{3}{|l|}{ Impact in terms of Skills } & \multicolumn{2}{|c|}{$\begin{array}{c}\text { Agree \& Strongly } \\
\text { Agree }\end{array}$} & \multirow{2}{*}{$\begin{array}{c}\text { Average } \\
\text { score } \\
4 \& 5\end{array}$} \\
\hline & 4 & 5 & \multicolumn{2}{|c|}{ (Score 4 and 5 ) } & \\
\hline 6. The course provides the necessary skills & 3 & 95 & 98 & 95.4 & \multirow{5}{*}{92.8} \\
\hline 7. The tools are easy to use & 2 & 89 & 91 & 92.6 & \\
\hline 8. The tools helps in modelling skills & 8 & 97 & 105 & 88.9 & \\
\hline 9. The skills acquired help in solving problems & 8 & 90 & 98 & 91.7 & \\
\hline 10. The skills acquired help in project development & 7 & 88 & 95 & 95.4 & \\
\hline
\end{tabular}

Figure 5: Result for Student's Performance

\section{Part 1: Reflections for Learning Knowledge}

On average, $92.4 \%$ students agree and strongly agree (score 4 and 5) that the lessons learned from the course are important and provide the necessary knowledge while carrying out these tasks. This tool can increase existing knowledge while contributing to the quality improvement in learning process.

\section{Part 2: Reflections on skills obtained}

On average, $92.8 \%$ students agree and strongly agree (score 4 and 5) that this course provides the necessary skills and the skills obtained can help in problem solving, project development and performance in learning. 


\subsection{Lecturer's performance}

Based on Figure 6, all lecturers gave positive feedback by rating score 4 and 5 (agree and strongly agree) for Part 1(reflections for learning knowledge) and Part 2 (reflections on skills obtained).

\section{Part 1: Reflections for Learning Knowledge}

On average, $100.0 \%$ lecturers agree and strongly agree (score 4 and 5 ) that the lessons learned from the course are important and provide the necessary knowledge while carrying out these tasks and courses as well can increase existing knowledge while contributing to improvement quality of work output.

\section{Part 2: Reflections on skills obtained}

On average, $100.0 \%$ lecturers agree and strongly agree (score 4 and 5) that this course provides the necessary skills and the skills obtained can help in solving problem while working. The skills obtained also contributes to the increase in work output.

\begin{tabular}{|c|c|c|c|c|c|}
\hline \multicolumn{3}{|l|}{ Learning Reaction } & \multirow{2}{*}{\multicolumn{2}{|c|}{$\begin{array}{c}\text { Agree \& Strongly } \\
\text { Agree } \\
\text { (Score } 4 \text { and 5) }\end{array}$}} & \multirow{2}{*}{$\begin{array}{c}\text { Average } \\
\text { score } \\
4 \& 5\end{array}$} \\
\hline & \multirow{2}{*}{$\begin{array}{l}4 \\
1\end{array}$} & \multirow{2}{*}{$\begin{array}{l}5 \\
9\end{array}$} & & & \\
\hline 1. The lessons learned from this course are important. & & & 10 & 100.0 & \multirow{5}{*}{100.0} \\
\hline 2. The lessons helps in learning necessary knowledge & 2 & 8 & 10 & 100.0 & \\
\hline 3. The course provides the necessary knowledge & 2 & 8 & 10 & 100.0 & \\
\hline 4. The knowledge gained can be relate to the theory concept & 0 & 10 & 10 & 100.0 & \\
\hline 5. The knowledge gained improve confidence to teach/learn & 3 & 7 & 10 & 100.0 & \\
\hline \multicolumn{3}{|l|}{ Impact in terms of Skills } & \multicolumn{2}{|c|}{$\begin{array}{c}\text { Agree \& Strongly } \\
\text { Agree }\end{array}$} & \multirow{2}{*}{$\begin{array}{c}\text { Average } \\
\text { score } \\
4 \& 5\end{array}$} \\
\hline & 4 & 5 & \multicolumn{2}{|c|}{ (Score 4 and 5 ) } & \\
\hline 6. The course provides the necessary skills & 0 & 10 & 10 & 100.0 & \multirow{5}{*}{100.0} \\
\hline 7. The tools are easy to use & 0 & 10 & 10 & 100.0 & \\
\hline 8. The tools helps in modelling skills & 2 & 8 & 10 & 100.0 & \\
\hline 9. The skills acquired help in solving problems & 4 & 6 & 10 & 100.0 & \\
\hline 10. The skills acquired help in project development & 3 & 7 & 10 & 100.0 & \\
\hline
\end{tabular}

Figure 6: Result for Lecture's Performance

\subsection{CONCLUSION}

A data model is a plan for creating and building a database. To be effective, it must be simple enough to communicate to the end user. The Entity-Relation Model (ER) is the most common method used to build data models for relational databases. Oracle Data Modeler is one of the powerful tools produced by Oracle Corporation to develop the logical model and physical model of a database. It provides services and tools that are easy to use and very helpful to students in improving their understanding and skills to develop ERD. ERD and Relational Model developed automatically by completing the variables or data required through the form-fills interface method. This method helps students to develop ERD quickly, easily and accurately. Most of the lecturers and students gave a positive reaction to the use of Data Modeler in teaching and learning process through Database Design course. On average, $100 \%$ lecturers and $92.4 \%$ students agree and strongly agree that Oracle Data Modeler give benefit for the use in teaching and learning purposes. For the impact on skills using this tools, on average $100 \%$ lecturers and $92.8 \%$ students agree and strongly agree that Oracle Data Modeler provides the necessary skills for them. Data Modeler gave positive impact on reaction of teaching and learning, improve lecturer and student's skills and help organization to involve in new technologies in teaching and learning activities. This study can improved for future field studies by looking at the use of Oracle SQL Developer in the development of database physical models and comparison with any other data modelers for database design. 


\section{References}

Simanjuntak, Hakim. 2013. Database Management System. http://pahamanandancontoh.blogspot.com/2013/02/databasemanagement-system.html, accessed March 20, 2014.

Sudirman. 2009. "Kinds of DBMS (Database Management System)". http://s3mrp.blogdetik.com/2009/11/04/macammacam-dbms-database-managemen-system/, accessed on International Journal Of Scientific \& Technology Research Volume 8, Issue 06, June 2019 Issn 2277-8616 312 Ijstr@2019 www.ijstr.org March 20, 2014

C.S.Miller, "What is a DBA" in Database Administration, 2ed edithition, publisher Addison Wesley,June 14, 2002, pp 9-65.

E.M.Bonk, "Computer Database Administrator", Career Information Center, USA, 2007. p116-117

Shang, P. (2016). Application and Exploration of Blended Learning Mode in the Teaching of Database Course Design. Advances in Computer Science Research, 59. 7th International Conference on Education, Management, Computer and Medicine (EMCM 2016). Atlantis Press.

Cvetanovic, M., Radivojevic, Z., Blagojevic, V., \& Bojovic, M. (2011). ADVICE - Educational System for Teaching Database Courses. IEEE Transactions On Education, 54(3), 398-409. 10.1109/TE.2010.2063431.

Zhuoyi, C., Na, L., \& Hongjie, Z. (2012). Exploration of Teaching Model of the Database Course Based on Constructivism Learning Theory

Oracle apps DBA field guide, available on :" http://fieldappsdba.blogspot.com/" , [Nov, 16 , 2013]

Rashid, T., \& AlRadhy, R. (2014). Transformations to Issues in Teaching, Learning, and Assessing Methods in Databases Courses. 2014 IEEE International Conference on Teaching, Assessment and Learning for Engineering (TALE).

Rashid, T. (2015). Investigation of Instructing Reforms in Databases. International Journal of Scientific \& Engineering Research, 6(8), 64-72.

Podeschi, RJ. (2016). Building I.S. Professionals through a Real World Client Project in a Database Application Development Course. Information Systems Education Journal (ISEDJ), 14(6), 34 40.

Saeed, S., Aamir, R., \& Mahmood, Z. (2011). Reflections on teaching database management systems to undergraduate students. International Journal of Education Economics and Development, 2(4), 398-411. doi : https://doi.org/10.1504/IJEED.2011.043834.

Nunnally, J. C. (1978). Psychometric theory (2nd ed.). New York: McGraw-Hill. 